\title{
Cost Optimization of a Tubular Steel Truss Using Limit State Method of Design
}

\author{
Ganesh Sanjay Mirajkar* \\ *(Assistant Professor, RMDSSOE, Warje, Pune, India)
}

\begin{abstract}
Limit state method helps to design structures based on both safety and serviceability. The structures are designed to withstand ultimate loads or the loads at which failure occurs unlike working stress method where only service loads are considered. This leads to enhanced safety. Also unlike the working stress method, the structures are economical. It is also better than ultimate load method as serviceability requirement is also taken care of by considering various safety factors for all the load types and structures do not undergo massive deflection and cracks. For tubular sections, higher strength to weight ratio could result in upto $30 \%$ savings in steel .Due to the high torsional rigidity and compressive strength, Tubular sections behave more efficiently than conventional steel section This study is regarding the economy, load carrying capacity of all structural members and their corresponding safety measures.
\end{abstract}

Keywords: IS (800-2007),IS(4923-1997),IS 806,IS 875, Tubular sections.

\section{INTRODUCTION}

Comparison of various structural elements in terms of Safety,Economy and Load carrying Capacity is done in paper Comparison Between Conventional Steel Structures and Tubular Steel Structures By Prof. M.G . Kalyanshetti and G.S.Mirajkar (myself) [11]. Experimental and theoretical studies have been carried by, S. Poonaya, U.Teeboonma, C.Thinvongpituk [9] regarding plastic collapse analysis of thin walled circular tubes subjected to bending. Design of circular steel arch with hollow sections is presented by C.A. Demopoulos, C.J.Gantes [10], they have suggested that Tubular sections are an economical, efficient and strong alternative to conventional sections used in steel structure A hollow section shall be designated by its outside dimensions and its thickness in millimeters and shall be further classified into CF or HF depending upon whether it is cold formed or hot formed.

a) A hot formed square hollow section with outside dimensions of $50 \mathrm{~mm}$ square and $2.90 \mathrm{~mm}$ thickness is designated as $50 \times 50 \times 2.90 \mathrm{HF}$ SHS.

b) A cold formed square hollow section without side dimensions of $50 \mathrm{~mm}$ square and $2.90 \mathrm{~mm}$ thickness is designated as $50 \times 50 \times 2.90$ CF SHS.

Strength of HF steel in N/mm ${ }^{2}$

\begin{tabular}{|l|l|l|}
\hline Grade & $\begin{array}{l}\text { Yield } \\
\text { Stress }\end{array}$ & $\begin{array}{l}\text { Tensile } \\
\text { Strength }\end{array}$ \\
\hline YST 210 & 210 & 330 \\
\hline YST 240 & 240 & 410 \\
\hline YST 310 & 310 & 450 \\
\hline
\end{tabular}

Classification of section as a plastic, compact, semicompact section is as per clause 3.7.2 and 3.7.4 of IS 800-2007

1.1 Tensile Strength: The design strength of a member under a tensile loading depends on the cross-sectional area and the design yield stress Factor Design strength shall be minimum of , $\mathrm{T}_{\mathrm{dg}}$ $\mathrm{T}_{\mathrm{dn}}, \mathrm{T}_{\mathrm{db}}$. (Clause: 6.2, 6.3\&6.4)

Where,

$\mathrm{T}_{\mathrm{dg}}=$ Strength in axial

Tension governed by

Yielding of gross section

Ag.f y $/ \gamma_{\mathrm{m} 0}$

$\mathrm{T}_{\mathrm{dn}}=$ Strength of plate in

Axial tension governed by Rupture of net cross

Sectional area at holes $0.9 \mathrm{~A}_{\mathrm{n}} \mathrm{fu} / \gamma_{\mathrm{m} 1}$

$\mathrm{T}_{\mathrm{dn}}=$ Rupture strength of an angle connected through one leg governed by rupture at net section $0.9 \mathrm{~A}_{\mathrm{nc}} \mathrm{f}_{\mathrm{u} /} \gamma_{\mathrm{m} 1} \beta \mathrm{A}_{\mathrm{go}} \mathrm{f}_{\mathrm{y}} / \gamma_{\mathrm{mo}}$

$\mathrm{T}_{\mathrm{db}}=$ strength of connection governed by block shear at an end connection of plates and angles=

$\mathrm{A}_{\mathrm{vg}} \mathrm{f}_{\mathrm{y}} /\left(\sqrt{ } 3 \gamma_{\mathrm{mo}}\right)+0.9 \mathrm{~A}_{\mathrm{n}} \mathrm{f}_{\mathrm{u}} / \gamma_{\mathrm{m} 1}$

(OR)

$\left[0.9 \mathrm{~A}_{\mathrm{vn}} \mathrm{f}_{\mathrm{u} /} / \sqrt{ } 3 \gamma_{\mathrm{m} 1+} \mathrm{A}_{\mathrm{tg}} \mathrm{f}_{\mathrm{y}} / \gamma_{\mathrm{m} 0}\right]$ Where,

$\mathrm{f}_{\mathrm{y}}=$ yield stress of material

$\mathrm{Ag}=$ gross area of cross

Section

$\gamma_{\mathrm{m} 0}=$ partial safety for failure in tension by

yielding $=1.10$

$\gamma_{\mathrm{m} 1=}$ partial safety factor for failure at ultimate 

ISSN : 2248-9622, Vol. 7, Issue 5, ( Part -I) May 2017, pp.29-32

stress $=1.25$

$\mathrm{f}_{\mathrm{u}}=$ ultimate stress of the material

$\mathrm{A}_{\mathrm{nc}}=$ net area of the connected leg

gross area of the outstanding leg

$\mathrm{A}_{\mathrm{go}}=$ gross area of the outstanding leg.

$\mathrm{L}_{\mathrm{C}}=$ length of the end connection

$\mathrm{A}_{\mathrm{vg}}, \mathrm{A}_{\mathrm{vn}}=$ minimum gross and net area in shear along bolt line parallel to external force respectively

1.2 compressive strength, $\mathrm{P}_{\mathrm{d}}=\mathrm{A}_{\mathrm{c}} \mathrm{f}_{\mathrm{cd}}$

value of $f_{c d}$ depends upon buckling curves (clause:7.1.2)IS 800-2007

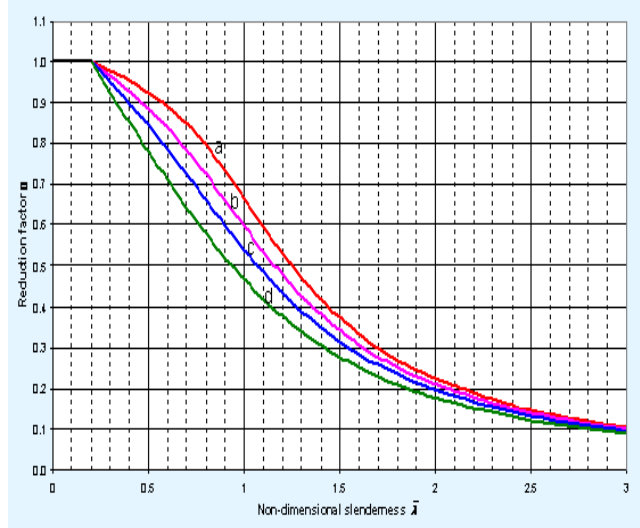

Figure1:.Geometry of truss

The selection of the buckling curve (i.e. $a, b, c, d$ ) depends on the cross section type.

For Hot Rolled Section: Buckling Class : a

1.3Flexural strength: Clause: IS 800

\section{PROBLEM.}

Configuration of truss is shown in fig 1.

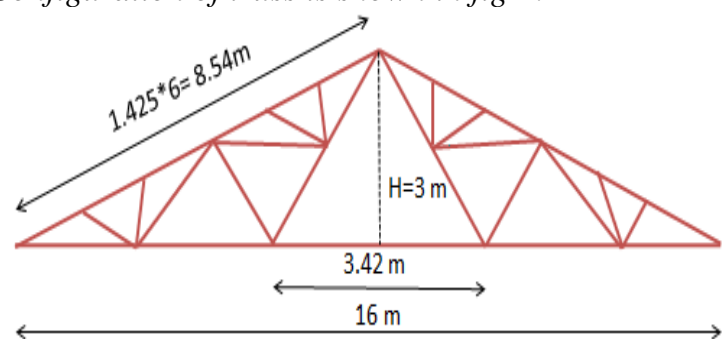

Figure2: Geometry of truss

1) Plan area around:- 550 sq.m.

2) Location: - Solapur, MIDC Area,

Maharashtra -India.

3) Roof truss:- FAN type

4) Geometry of truss:- $\operatorname{span} 24 \mathrm{~m}, \theta=16.26^{\circ}$,

5) 10 panel Points spacing of purlins $1.425 \mathrm{~m}$

6) Length of sheet $=3.05 \mathrm{~m}$, sloping length $=12.5 \mathrm{~m}$.

7) Spacing of truss $=5 \mathrm{~m}$, No of trusses $=811$

\section{APPROACH}

1. Dead load analysis is done according to IS 875 (Part1) with the help of STAAD-PRO

2. Live load analysis is done according to IS 875

(Part2) with the help of STAAD-PRO

3 . Wind load analysis is done according to IS 875 ((part 3) with the help of STAAD-PRO

4. Designing is done according to IS 800,IS806 and STAAD PRO

Conventional design is carried out as per IS 8002007 and tubular sectioned design is carried out as per IS 806.

A)Total Dead Load.

1) On central purlin $=2.411 \mathrm{kN}$

2) On intermediate purlin $=2.411 \mathrm{kN}$

3) On end purlin $=2.411 \mathrm{kN}$

B) Total Live Load

1) On central purlin $=1.755 \mathrm{kN}$

2) On intermediate purlin $=1.755 \mathrm{kN}$

3) On end purlin $=1.755 \mathrm{kN}$

C) Total Wind Load

1) On central purlin $=-6.722 \mathrm{kN}$

2) On intermediate purlin $=-6.722 \mathrm{kN}$

3) On end purlin=- $6.722 \mathrm{kN}$

Using above results design is carried out for required load carrying capacity. Optimum sections are assigned to truss members and purlin members. Comparison is made for self-weight and cost of various elements of truss such as principalrafter,tie member, strut member, sling member, purlin member. Results for single truss are presented graphically in graph 1 to graph 5. These results shows that considerable amount of saving is achieved using Tubular sections Also analysis is carried out for total shed area of 800 sq.m. Consisting 8 numbers of trusses. In this case also comparison is made for various elements of truss. Results are presented in tabular form i.e. Table 1 to table 5 . Study reveals that considerable saving in cost can be achieved by using tubular sections

Graph 1. variation of design weights for Principal Rafter of Fan Truss

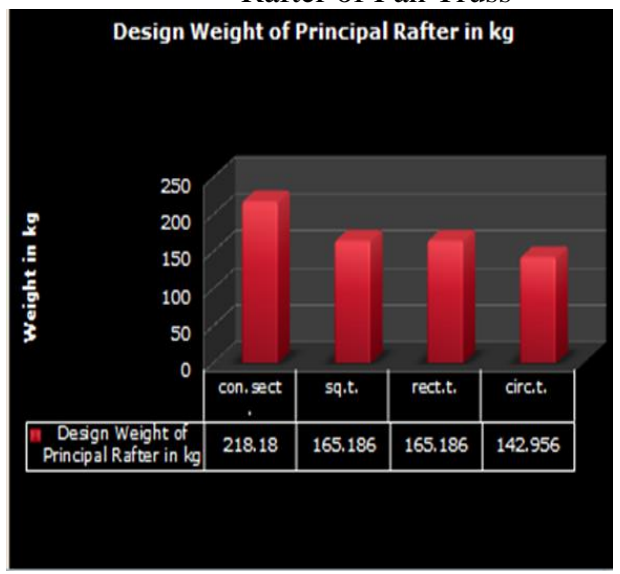


Graph 2. variation of design weights for Tie Member of Fan Truss

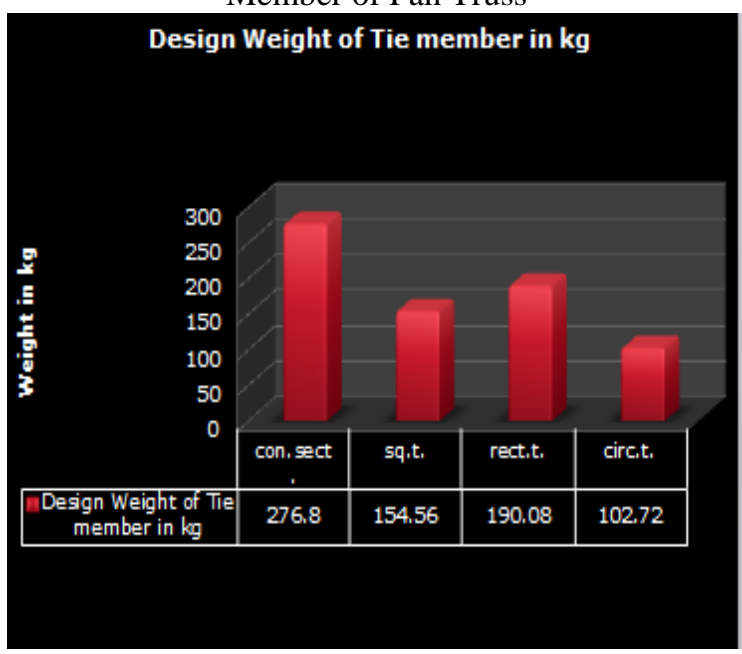

Graph 3. variation of design weights for Strut member of Fan Truss

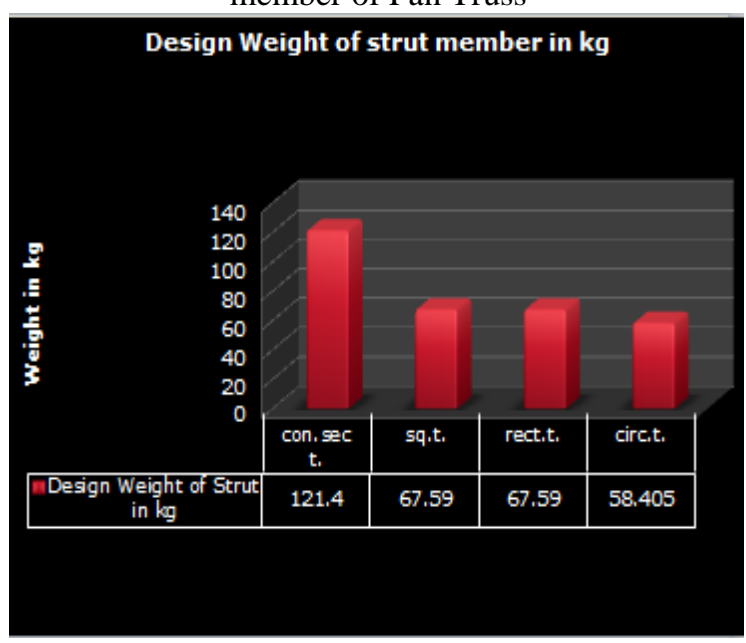

Graph 4. variation of design weights for Sling member of Fan Truss

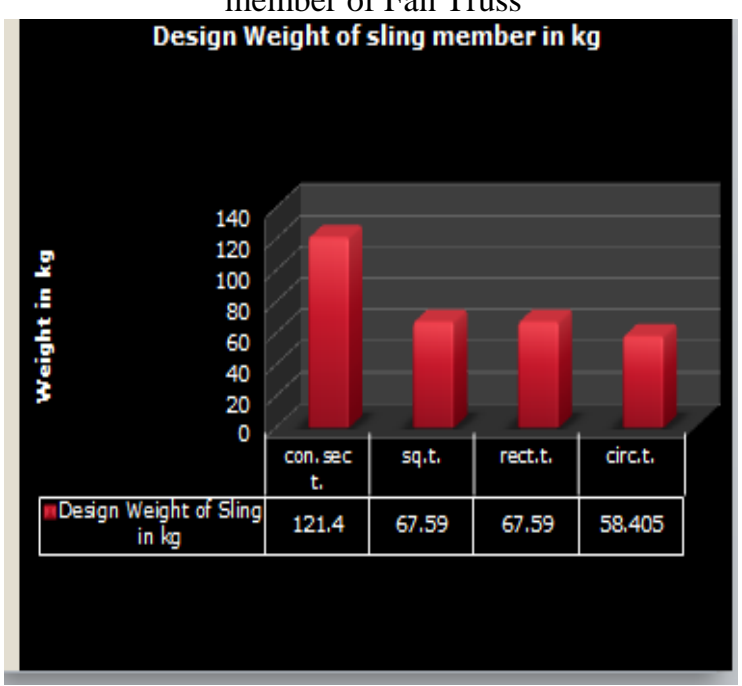

Graph 5. variation of design weights for Purlin member of Fan Truss

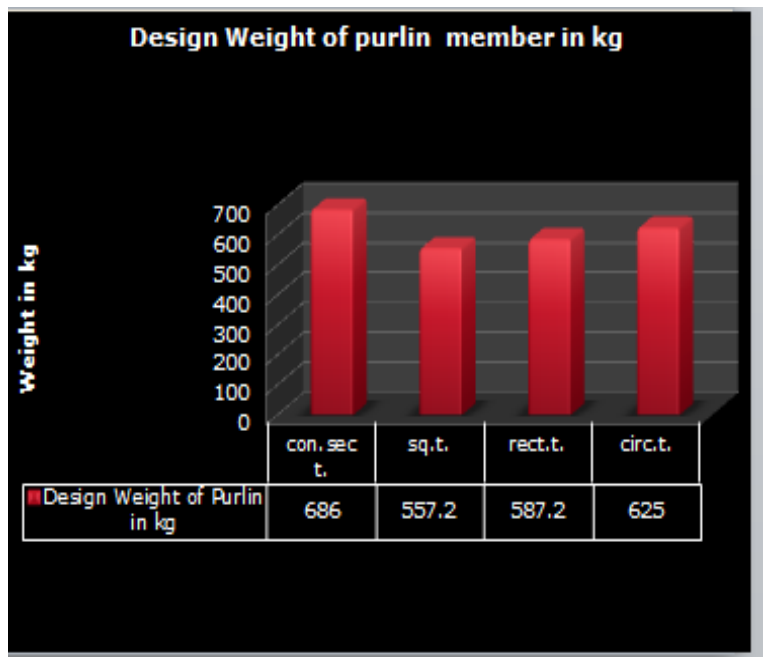

IV. TOTAL COST

Table 1: Sections Assigned:

\begin{tabular}{|c|c|c|c|c|}
\hline section & conventional & Square Tube & Rect tube & Circ tube \\
\hline Prin. Ratter & 2ISA 55X55X8 & $72 \times 72 \times 4.8$ & $96 \times 48 \times 4.8$ & OD 88.9,NB=80,t=4 \\
\hline Tie member & $\begin{array}{c}2 \text { ISA } \\
100 \times 100 \times 10\end{array}$ & $72 \times 72 \times 4.8$ & $96.48 \times 4.8$ & OD 88.9,NB=80,t=4 \\
\hline strut & ISA $65 \times 45 \times 6$ & ISA 50X50X2.9 & ISA 60XXOX2.9 & $N B=40,0 D=48.3, t=4$ \\
\hline Sling & ISA 70X50X8 & $50 \times 50 \times 2.9$ & $60 \times 40 \times 2.9$ & $\mathrm{NB} 40,0 \mathrm{D} 48.3, \mathrm{t}=4$ \\
\hline purlin & ISA $125 \times 95 \times 12$ & $113.5 \times 113.5 \times 4.8$ & $145 \times 82 \times 4.8$ & 0D139.7,NB125,t=4,5 \\
\hline
\end{tabular}

Total cost for modified Fan truss truss using conventional sections: Rs 3,31,558

Total cost for modified Fan truss using square tube sections: Rs 2,48,118/-. (\% saving in cost $=25.16 \%$ )

Total cost for Fan truss using rectangular tub tubee sections: Rs 2,62,008 /- (/\% saving in cost $=20.9 \%)$. Total cost for modified Fan truss using circular tube sections: Rs 2,10,554 /- (\% saving=36.4\%)

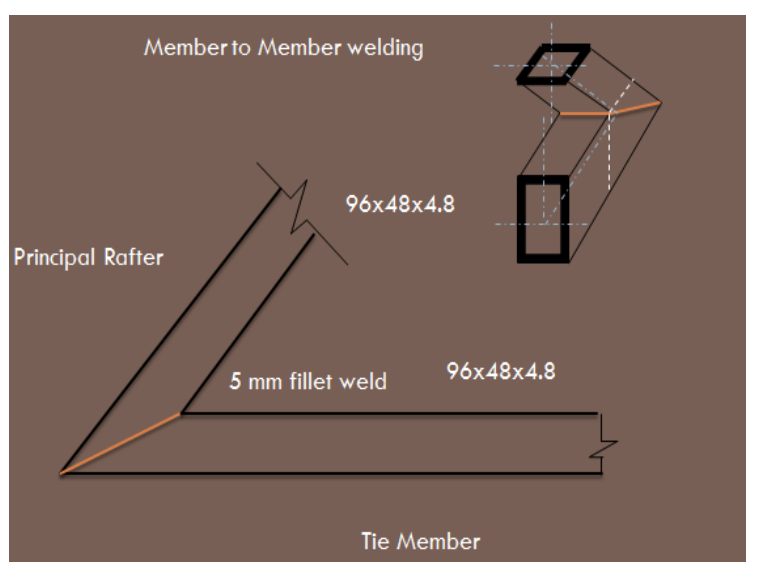

Figure3.Connection 


\section{CONCLUSION}

Above study reveals that tubular sections proves to be economical. Total saving of almost 20 $\%$ to $40 \%$ in cost is achieved. Out of circular, square and rectangular shapes, due to connection difficulties of circular tube sections, it is suggested to adopt rectangular or square tube sections. This study is for a given area of 550 sq.m. and truss of Fan type. Effectiveness of Tubular section can be verified for different plan areas for various types of trusses.

From above observations and results one can conclude that, the structural members having larger unsupported lengths can be assigned tubular sections which will derive overall economy. For smaller unsupported lengths one will have to assign minimum sections for both conventional and tubular sections so that economy is not considerably achieved. In such cases due to larger initial cost it becomes uneconomical. Initial cost for tubular sections is more however, due to reduction in total dead weight, it is overall economical not only for industrial buildings but also for various steel structures like transmission towers, bridge structures etc

\section{REFERANCES}

[1]. IS 800-1984, Code of practice for general construction i in steel.

[2]. IS 875-1987(part-1) Code of practice for design loads (other than earthquake) for buildings and structures.

[3]. IS 875-1987(part-2) Code of practice for design loads (other than earthquake) for buildings and structures

[4]. IS 875-1987(part-3) code of practice for design loads (other than earthquake) for buildings and structures

[5]. IS 806-code of practice for use of steel tubes) for buildings and structures.

[6]. Design of steel structure by S.K. DUGGAL.

[7]. Design of steel structure by Ashok Kumar Jain.

[8]. Broucher of Tata steel structures.

[9]. "Plastic collapse analysis of thin walled circular tubes subjected to bending" by S. Poonaya, U.Teeboonma, C.Thinvongpituk, 15 th may 2008.

[10]. "Design of circular steel arch with hollow sections" by C.A. Demopoulos, C.J. Gantes_Department of Civil Engineering, National Technical University of Athens, Greece , 10 June 2007.ic

[11]. "Comparison Between Conventional Steel Structures And Tubular Steel Structures" by Prof.M.G.Kalyanshetti,G.S.Mirajkar,Nov-Dec 2012. 